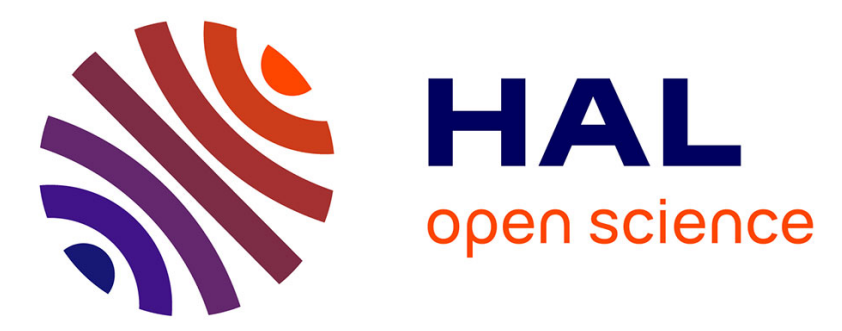

\title{
Short-term response of the slow growing seagrass to simulated anchor impact
}

Ceccherelli Giulia, Campo Davide, Milazzo Marco

\section{To cite this version:}

Ceccherelli Giulia, Campo Davide, Milazzo Marco. Short-term response of the slow growing seagrass to simulated anchor impact. Marine Environmental Research, 2007, 63 (4), pp.341. 10.1016/j.marenvres.2006.10.004 . hal-00501891

\section{HAL Id: hal-00501891 https://hal.science/hal-00501891}

Submitted on 13 Jul 2010

HAL is a multi-disciplinary open access archive for the deposit and dissemination of scientific research documents, whether they are published or not. The documents may come from teaching and research institutions in France or abroad, or from public or private research centers.
L'archive ouverte pluridisciplinaire HAL, est destinée au dépôt et à la diffusion de documents scientifiques de niveau recherche, publiés ou non, émanant des établissements d'enseignement et de recherche français ou étrangers, des laboratoires publics ou privés. 


\section{Accepted Manuscript}

Short-term response of the slow growing seagrass posidonia oceanica to simulated anchor impact

Ceccherelli Giulia, Campo Davide, Milazzo Marco

PII:

S0141-1136(06)00191-7

DOI:

10.1016/j.marenvres.2006.10.004

Reference:

MERE 3072

To appear in:

Marine Environmental Research

Received Date: $\quad 10$ May 2006

Revised Date: $\quad 9$ October 2006

Accepted Date: 13 October 2006

Please cite this article as: Giulia, C., Davide, C., Marco, M., Short-term response of the slow growing seagrass posidonia oceanica to simulated anchor impact, Marine Environmental Research (2006), doi: 10.1016/j.marenvres. 2006.10.004

This is a PDF file of an unedited manuscript that has been accepted for publication. As a service to our customers we are providing this early version of the manuscript. The manuscript will undergo copyediting, typesetting, and review of the resulting proof before it is published in its final form. Please note that during the production process errors may be discovered which could affect the content, and all legal disclaimers that apply to the journal pertain. 


\title{
SHORT-TERM RESPONSE OF THE SLOW GROWING SEAGRASS POSIDONIA OCEANICA TO SIMULATED ANCHOR IMPACT
}

\author{
CECCHERELLI Giulia $^{\circ}$, CAMPO Davide` $^{\wedge}$ and MILAZZO Marco
}

${ }^{\circ}$ Dipartimento di Botanica ed Ecologia vegetale, Università di Sassari, via F Muroni 25, 07100 Sassari, Italy

^I.C.R.A.M. Struttura tecnico Scientifica di Palermo, via E Amari 124, 90139 Palermo, Italy

“Dipartimento di Biologia Animale, Università di Palermo, via Archirafi 18, 90123

Palermo, Italy

*Corresponding author: cecche@uniss.it

Tel: +39-079-228642

Fax: +39-079-233600 
Key-words: anchoring, clonal integration, disturbance, Posidonia oceanica, seagrass.

\begin{abstract}
Experimental evaluations about the impact of anchors of small vessels have previously shown that each anchoring can on average damage up to 6 shoots of Posidonia oceanica, removing small amount of biomass and, at the same time, interrupting continuity among shoots. The aim of the paper was to investigate the response of $P$. oceanica to different damage intensity at two levels of substrata compactness. Three treatments were considered: Control (no damage); Low damage (simulated anchor damage by 3 strokes of a hoe); High damage (6 strokes). Disturbance was higher where the substratum was highly penetrable and after one year significant variation was observed among treatments for both the number of leaves per shoot and shoot density. Conversely, the number of leaves per shoot by the end of the study was similar among all treatment combinations, suggesting that this was the only phenological feature that recovered, and probably the only result that through clonal integration could be achieved. These data strongly highlighted the role that anchoring might have on the slow growing seagrass $P$. oceanica meadow.
\end{abstract}




\section{INTRODUCTION}

World-wide seagrass loss has been reported from a variety of both direct and indirect human-induced influences (Hemminga \& Duarte, 2000). Among all the causes, some are responsible for large scale seagrass decline, such as eutrophication, industrial runoff, oil spillage, dredging (e.g. Short, Ibelings \& den Hartog, 1988; Preen, Lee Long \& Coles, 1995). Conversely, propellers and anchors only cause small gaps within the seagrass meadow, by removal of plant biomass depending on anchor size and type (Porcher, 1984; Walker, Lukatelich, Bastyan \& McComb, 1989; Creed \& Amado Filho, 1999; Rasheed, 1999; Francour, Ganteaume \& Poulain, 1999; Milazzo, Badalamenti, Ceccherelli \& Chemello, 2004).

Because loss of seagrasses within meadows has been quite well documented, information about the recovery capacity of seagrasses to all forms of disturbance have become particularly important, so that proper evaluations on the effective impact could be done. For example, seagrass recovery to physical damage was quite unknown until recently. Overall, recovery seems to be mostly due to vegetative propagation and, therefore, recovery time seems highly variable, being dependent upon species growth rate. For example, Creed and Amado Filho (1999) found that Halodule wrightii (Ascherson)

recovered from $0.25 \mathrm{~m}^{2}$ gaps in 9 months, while Rasheed (1999) found Zostera capricorni (Ascherson) recovered after 12 months from the same clearing plot size.

However, data for seagrass recovery are particularly needed for slow growing species (Meehan \& West 2000). Zieman (1976) and Williams (1988) provided data for recovery of Thalassia testudinum (Banks ex Konig) which seems a much slower recovery 
species with only minimal colonisation of anchor scars occurring after 7 months. A recent paper by Gonzàlez-Correa, Bayle, Sànchez-Lizaso, Valle, Sàanchez-Jerez \& Ruiz (2005) has highlighted the recovery capacity of Posidonia oceanica (L., Delile) to illegal otter trawling, although the performance of this seagrass seems much faster at control sites where meadows are much denser and resuspension of sediments was lower. Other predictions on the recovery rate to mechanical disturbances could only be done indirectly on the basis of data on population dynamics, seasonal and annual growth, and productivity of all seagrasses (e.g. Marbà, Cebriàn, Enriquez \& Duarte, 1996; Marbà, Duarte, Cebriàn, Gallegos, Olesen \& Sand-Jansen 1996; Vermaat, Agawin, Duarte, Fortes, Marbà \& Uri, 1995; Pergent-Martini, Rico-Raimondo \& Pergent, 1994; Alcoverro, Duarte \& Romero, 1995; Marbà \& Duarte, 1997).

Due to the spatial extent of Posidonia oceanica meadows and its high productivity, it is a major component of the Mediterranean coastal system (Buia, Zupo \& Mazzella, 1992; Pergent, Rico-Raimondo \& Pergent-Martini, 1997), where it plays a very important role sheltering understoried and speciose assemblages (e.g. Macpherson, Biagi, Francour, Garcia-Rubies, Harmelin \& Harmelin-Vivien et al., 1997; Guidetti, 2000). P. oceanica ranks among the longest-lived seagrasses (Duarte 1991) exhibiting very slow growth rate (Cebrian, Duarte, Marbà \& Enrìquez, 1997).

Experimental evaluations of the impact of anchors have suggested that Posidonia oceanica is differently affected by anchors depending on the anchor model used (4 $\mathrm{kg}$ in weight) (Milazzo, Badalamenti, Ceccherelli \& Chemello, 2004). In particular, the use of the Hall type anchor has a lower impact than Danforth and Folding grapnel anchors. Each complete anchoring cycle (e.g. anchor fall, dragging/lock-in and weighing) can uproot or 
break on average up to 6 shoots and create discontinuity among shoots within the meadows.

In this paper we examine the short-term response of Posidonia oceanica to simulated anchoring. By experimentally scarring the meadow we reproduced the damage provoked by a Folding grapnel anchor, which was found to be the highest impacting anchor (Milazzo, Badalamenti, Ceccherelli \& Chemello, 2004). The aim of the paper was to estimate $P$. oceanica changes in above ground biomass after being damaged: the response to different damage intensity at two levels of substrata compactness was evaluated.

Substratum compactness, and thus penetration, was evaluated as a possible important source of variation in damage intensity. In particular, the lower the compactness the higher is the probability expected for rhizomes to be uprooted. The higher the compactness the lower should be the number of shoots uprooted.

\section{MATERIALS AND METHODS}

The study was carried out in a shallow (2 $\mathrm{m}$ depth) Posidonia oceanica meadow located at Stagnone, $\left(37^{\circ} 52^{\prime} 32^{\prime \prime} \mathrm{N}\right.$ and $\left.12^{\circ} 26^{\prime} 17^{\prime \prime} \mathrm{E}\right)$ along the western coast of Sicily, which is a particularly sheltered and little frequented site. Within this meadow 12 areas (about $3 \times 3 \mathrm{~m}$ in size) were chosen so that 6 were on substratum highly penetrable and the other 6 on substratum which was less penetrable. Penetration of the substratum was quantified by using a penetrometer such as that used by Francour, Ganteaume \& Poulain (1999). A $2 \mathrm{~m}$ long, $8 \mathrm{~mm}$ diameter rod was placed perpendicularly to the bottom and a 5 $\mathrm{kg}$ weight was dropped $50 \mathrm{~cm}$ on to a stop in the middle of the rod. The impact of the 
weight hitting the stop provided a constant force to drive the rod into the rhizome mat. This measurement was repeated randomly at the site 20 times to define areas of different compactness. Weak substratum compactness refers to a mean penetration depth of $26.6 \mathrm{~cm}$ $( \pm 2.1 \mathrm{SD})$, while high compactness refers to a mean penetration of $9.2 \mathrm{~cm}( \pm 1.9 \mathrm{SD})$. At the high penetration areas a higher shoot density and proportion of orthotropic shoots was found, while at low penetration areas a higher sediment accumulation was observed. In each of these areas 3 replicated experimental units $(40 \times 40 \mathrm{~cm}$ in size $)$ were randomly selected and marked at the corners with plastic stakes $(35 \mathrm{~cm}$ in length). Within these areas anchor damage was experimentally simulated by using a garden hoe. It was impractical to use a real anchor because it was not possible to throw an anchor several times in the same experimental area. The three treatments considered are: Control (no simulated anchor damage); Low damage (3 strokes); High damage (6 strokes). Strokes were given as simulation of the damage caused by folding grapnel anchor (Milazzo et al., 2004); the hoe was drawn through the sediment face on so that it ploughed like an anchor. The three treatments were randomly assigned to the six areas within each compactness group, so that two areas belonged to the same compactness $\times$ damage combination of treatments. All the 36 experimental units established occurred within a $120 \mathrm{~m}^{2}$ area.

Damage treatments were carried out on December 2000 and recovery after damage was evaluated by sampling every month until November 2001, as we believed that it was a feasible time period to detect a response of the plant. The response variables considered were plant leaf number per shoot, leaf length and shoot density, as they are the common phenological variables to evaluating the aboveground biomass performance of this 
seagrass. They were all evaluated in the field: shoot density was estimated by counting the number of shoots in each experimental unit, while leaf length (the length of the longest leaf in the shoot) and leaf number (adult, intermediate and juvenile leaves in the shoot) were estimated by choosing two shoots at random within each unit.

A multifactorial analysis of variance was performed on data taken at the last sampling time for each response variable. 'Penetration' (2 levels) and 'damage' (3 levels) were treated as fixed and orthogonal, while 'area' (2 levels) as random nested in their interaction. For leaf length and number 'experimental unit' (3 levels) was also considered and treated as random nested in area. Cochran's test was performed for all analyses to check for homogeneity of variances. Post-hoc multiple comparisons were done using SNK test (Underwood, 1997).

\section{RESULTS AND DISCUSSION}

Estimation in the field of the biomass of Posidonia oceanica removed or broken due to strokes of the hoe, because it was not possible to collect fragments of leaves in the water column. However, the impact on shoot density was estimated by counting the shoots in each unit before and right after damaging: at the low and high damage treatment 11.16 $( \pm 1.44)$ and $13.80( \pm 2.24), 7.00( \pm 0.68)$ and $11.3( \pm 1.33)$ were the mean number of shoots

( \pm SE) removed per plot, at weak and high compactness, respectively (Fig.1). The mean number of shoots removed in the experiment at low damage and weak compactness was equivalent to about the effect of one anchoring cycle, while in the other three combinations of treatment the mean number of shoots removed was equivalent to about two anchoring cycles. 
Each response variable analysed in this study has given a specific result to the experimental damage of the plants. For example, after one year, leaf number per shoot was not affected by damaging (Fig 2a and b, Table 1). Although differences among treatments were evident after a few months, especially at high penetration of substratum (Fig 2b), analysis performed using November 2001 data did not detect significant differences. The patterns found suggest that plant recovery in leaf number per shoot occurred during the study period.

Conversely, leaf length was still affected by experimental damage even after one year (Table 1 and Fig 2c and d). In fact, analysis of data has detected that the shortest size was found at a high level of damage, while leaf length in control and medium damaged plots were similar (SNK test, Table 1). Although no analysis has been performed on previous sampling times, differences among treatments could have changed through time being more evident in the latter period at low penetration condition (Fig. 2c). Evident temporal variations were found through the study period at both types of substratum, according to patterns already described extensively (Pergent-Martini, Rico-Raimondo \& Pergent, 1994; Alcoverro, Duarte \& Romero, 1995; Marbà, Cebriàn, Enriquez \& Duarte, 1996; Cebriàn, Duarte, Marbà \& Enrìquez, 1997).

Overall, among the three response variables, $P$. oceanica shoot density was the most affected by experimental damaging especially where the substratum was highly penetrable (Table 1 and Fig 2e and f). A significant interaction between substratum penetration and damage intensity was found. In fact, at low penetration of substratum, high and medium levels of damage had a similar effect on shoot density but one year after the damage were similar to the controls. Conversely, at high penetration three very different shoot densities 
occurred among levels of damage intensity. Possibly, where substratum is highly compact (low penetration) $P$. oceanica was better able to resist the simulated anchor strokes and a lower number of shoots were uprooted, compared to the low compactness (high penetration) areas. This could be corroborated by the similarity in mean shoot density among levels of damage at low penetration, rather that at high penetration, in December 2000. In fact, data taken before and right after damaging estimated mean values of 11.16 and 7.0 shoots removed where damage was low, while 13.83 and 11.33 where damage was high, at high and low compactness, respectively (Fig.1). However, although at high compactness the initial shoot density was apparently very similar among the three treatments, it was very evident that through time differences among them increased. Although the hoeing of low penetration substrate could not uproot but only initially damage shoots, the detachment of shoots occurred later over a period of three months. Nevertheless, this finding might indicate a different impact of simulated anchors on Posidonia oceanica shoot density depending on the substratum penetration. Unfortunately, the effect of Time $\times$ Damage $\times$ Substratum penetration interaction could not be estimated because the assumption of independence of data by time would have not been met. However, graphical inspection could easily bring further evidence to the model that differences found at the end of the study are basically due to the different impact and not to a different recovery pattern. We believe that different features that are likely to occur at the two substratum types, such as sediment mobility and nutrient availability for roots, did not affect recovery but are merely affecting natural spatial variability of $P$. oceanica shoot density independently of the impact (e.g. Balestri, Cinelli \& Lardicci, 2003).

In summary, damage caused by folding grapnel anchors, although considered small 
scale damage, can create an impact on Posidonia oceanica, particularly to shoot density, from which it is very difficult to recover in the short-term. This result was not unexpected given the slow pattern of growth demonstrated in several studies for this species (PergentMartini, Rico-Raimondo \& Pergent, 1994; Alcoverro, Duarte \& Romero, 1995; Vermaat, Agawin, Duarte, Fortes, Marbà \& Uri, 1995; Marbà, Cebriàn, Enriquez \& Duarte, 1996; Marbà, Duarte, Cebriàn, Gallegos, Olesen \& Sand-Jansen 1996; Marbà \& Duarte, 1998). Moreover, as the holes created by the anchors and other impacts can take a long time to be re-colonised, the possible increase in sediment mobility due to holes could be a further indirect cause of disturbance affecting recovery through time. Conversely, the most interesting result could be that the number of leaves per shoot was the only response variable recovered within one year, probably due to resource reallocation through modules. Overall, this gives good estimates on the quantitative and qualitative short-term response of $P$. oceanica suggesting that biomass allocation after a stress is addressed in terms of the number of leaves per shoot.

Consideration should be given to the possible influence of clonal integration, among shoots of Posidonia oceanica. Indeed, anchor damage may be responsible for module discontinuity, through breakage of rhizomes, besides biomass removal, through both uprooting shoots and breakage of leaves (apex up to portions of several centimetres in length). For the findings about the importance of nutrient mobility through modules collected for P. oceanica and other seagrasses (e.g. Libes \& Boudouresque, 1987; Nielsen \& Pedersen, 2000; Marbà, Hemminga, Mateo, Duarte, Mass, Terrados et al., 2002) and stressed by Kendrick, Duarte \& Marbà (2005), module interruption could deplete efforts from neighbouring shoots of the same clone. So, whether interruption among shoots 
occurs, leaf production rate could be decreased and not be able to cope with the leaves' removal within 1 year. This could be the reason for the low leaf length of shoots at highly impacted plots, even at the end of the study.

Unfortunately, in this experiment, treatments have been attributed to several areas within a $P$. oceanica meadow regardless of clonality, and whether shoots occurring in the same plot belong to the same clone remains unknown. Also, identification of clone dimension at the study site could help to interpret the very high recruitment rate of shoots (e.g. Vermaat, Agawin, Duarte, Fortes, Marbà \& Uri, 1995; Marbà, Cebriàn, Enriquez \& Duarte, 1996) observed at controls. This finding could lead to the possibility that biomass removal of a clonal individual could off set by an increase growth in other 'communicating' portions. However, only properly designed experiments could investigate the influence of clonality on recovery from damage, estimating the distances to which integration among shoots could occur in the field.

Overall, the results obtained within this study strongly highlighted the role that anchor activity, even by small vessels, might have on $P$. oceanica meadow representing a small-scale but affective cause of degradation. The frequency of anchoring at some visited sites, in terms of number of boats and extension of the visitation period, could make this chronic disturbance very stressful to the growth of the seagrass over several years.

\section{ACKNOWLEDGEMENT}

This work was in part supported by PADI AWARE. 


\section{REFERENCES}

Alcoverro, T., Duarte, C.M., Romero, J. (1995). Annual growth dynamics of Posidonia oceanica: contribution of large-scale versus local factors to seasonality. Marine Ecology Progress Series 120, 203-210.

Balestri, E., Cinelli, F., Lardicci, C. (2003). Spatial variation in Posidonia oceanica structural, morphological and dynamic features in a northwestern Mediterranean coastal area: a multi-scale analysis. Marine Ecology Progress Series 205, 51-60.

Buia, M.C., Zupo, V., Mazzella, L. (1992). Primary production and growth dynamics in Posidonia oceanica. Marine Ecology: PSZNI 13, 2-16.

Cebrian, J., Duarte, C.M., Marbà, N., Enrìquez, S. (1997). Magnitude and fate of the production of four co-occurring Western Mediterranean seagrass species. Marine Ecology Progress Series 155, 29-44.

Creed, J.L., \& Amado Filho, G.M. (1999). Disturbance and recovery of the macroflora of a seagrass (Halodule wrightii Ascherson) meadow in the Abrolhos Marine National Park, Brazil: an experimental evaluation of anchor damage. Journal Experimental Marine Biology and Ecology 235, 285-306.

Duarte, M.C. (1991). Variance and the description of nature: In: Cole, J.J. (Ed.), Comparative ecology of ecosystems: patterns mechanisms and theories. SpringerVerlag, Heidelberg, pp. 301-318.

Francour, P., Ganteaume, A., Poulain, M. (1999). Effects of boat anchoring in Posidonia oceanica seagrass beds in the Port-Cros National Park (north-western Mediterranean Sea). Aquatic Conservation: Marine Freshwater Ecosystem 9, 391400. 
Gonzàles-Correa, J.M., Bayle, J.T., Sànchez-Lizaso, J.L., Valle, C., Sàanchez-Jerez, P., Ruiz, J.M. (2005). Recovery of deep Posidonia oceanica meadows degraded by trawling. Journal Experimental Marine Biology and Ecology 320, 65-76.

Guidetti, P. (2000). Differences among fish assemblages associated with nearshore Posidonia oceanica seagrass beds, rocky-algal reefs and unvegetated sand habitats in Adriatic Sea. Estuarine, Coastal Shelf and Science 50, 515-529.

Hemminga, M.A., \& Duarte, C.M. (2000). Seagrass Ecology. Cambridge: Cambridge University.

Kendrick, G.A., Duarte, C.M., Marbà, N. (2005). Clonality in seagrasses, emergent properties and seagrass landscape. Marine Ecology Progress Series 290, 291-296.

Libes, M., \& Boudouresque, C.F. (1987). Uptake and long-distance transport of carbon in the marine phanerogam Posidonia oceanica. Marine Ecology Progress Series $38,177-186$.

Macpherson, E., Biagi, F., Francour, P., Garcia-Rubies, A., Harmelin, J., Harmelin-Vivien, M., Jouvenel, J.Y., Planes, S., Vigliola, L., Tunesi, L. (1997). Mortality of juvenile fishes of the genus Diplodus in protected and unprotected areas in the western Mediterranean Sea. Marine Ecology Progress Series 160, 135-147.

Marbà, N., \& Duarte, C.M. (1997). Interannual changes in segrass (Posidonia oceanica) growth and environmental change in the Spanish Mediterranean littoral zone. Limnology and Oceanography 42, 800-810.

Marbà, N., \& Duarte, C.M. (1998). Rhizome elongation and seagrass clonal growth. Marine Ecology Progress Series 174, 269-280. 
Marbà, N., Cebriàn, J., Enrìquez, S., Duarte, C.M. (1996). Growth patterns of Western Mediterranean seagrasses: species-specific responses to seasonal forcing. Marine Ecology Progress Series 133, 203-215.

Marbà, N., Duarte, C.M., Cebriàn, J., Gallegos, M.E., Olesen, B., Sand-Jansen, K. (1996). Growth and population dynamics of Posidonia oceanica on the Spanish Mediterranean coast: elucidating seagrass decline. Marine Ecology Progress Series 137, 203-213.

Marbà, N., Hemminga, M.A., Mateo, M.A., Duarte, C.M., Mass, Y.E.M., Terrados, J., Gacia, E. (2002). Carbon and nitrogen translocation between seagrass ramets. Marine Ecology Progress Series 226, 287-300.

Meehan, A.J., \& West, R.J. (2000). Recovery times for a damaged Posidonia australis bed in south eastern Australia. Aquatic Botany 67, 161-167.

Milazzo, M., Badalamenti, F., Ceccherelli, G., Chemello, R. (2004). Boat anchoring on Posidonia oceanica beds in a marine protected area (Italy, Western Mediterranean): effect of anchor types in different anchoring stages. Journal Experimental Marine Biology and Ecology 299, 51-62.

Nielsen, S.L., \& Pedersen, M.F. (2000). Growth, photosynthesis and nutrient content of seedlings and mature plants of Cymodocea nodosa- the importance of clonal integration. Aquatic Botany 68, 265-271.

Pergent-Martini, C., Rico-Raimondo, V., Pergent, G. (1994). Primary production of Posidonia oceanica in the Mediterranean Basin. Marine Biology 120, 9-15.

Pergent, G., Rico-Raimondo, V., Pergent-Martini, C. (1997). Fate and production in Posidonia oceanica meadows of the Mediterranean. Aquatic Botany 59, 307-321. 
Porcher, M. (1984). Impact de mouillages forains sur le herbiers à Posidonia oceanica. In: Boudouresque, C.F., de Grissac, A.J. \& Oliver, J., (Ed.), International Workshop on Posidonia oceanica Beds. GIS Posidonie Publ., Marseille, pp. 145148.

Preen, A., Lee Long, W.J., Coles, R.G. (1995). Flood and cyclone related loss, and partial recovery, of more than $1,000 \mathrm{~km}^{2}$ of seagrass in Hervey Bay, Queensland, Australia. Aquatic Botany 52, 3-17.

Rasheed, M.A. (1999). Recovery of experimentally created gaps within a tropical Zostera capricorni (Aschers.) seagrass meadow, Queensland Australia. Journal of Experimental Marine Biology and Ecology 235, 183-200.

Short, F.T., Ibelings, B.W., den Hartog, C. (1988). Comparison of a current disease to the wasting disease in the 1930's. Aquatic Botany 30, 295-304.

Underwood, A.J. (1997). Experiments in ecology: their logical design and interpretation using analysis of variance. Cambridge: Cambridge University Press.

Vermaat, J.E., Agawin, N.S.R., Duarte, C.M., Fortes, M.D., Marbà, N., Uri, J.S. (1995). Meadow maintenance, growth and productivity of a mixed Philippine seagrass bed. Marine Ecology Progress Series 124, 215-225.

Walker, D.I., Lukatelich, R.J., Bastyan, G., McComb, A.J. (1989). Effect of boat moorings on sea beds near Perth, Western Australia. Aquatic Botany 36, 69-77.

Williams, S.L. (1988). Thalassia testudinum productivity and grazing by green turtles in a highly disturbed seagrass bed. Marine Biology 98, 447-455.

Zieman, J.C. (1976). The ecological effects of physical damage from motor boats on turtle grass beds in southern Florida. Aquatic Botany 2, 127-139. 


\section{ACCEPTED MANUSCRIPT}

\section{Legends}

Fig. 1 Posidonia oceanica. Mean ( \pm SE) shoot density $(n=6)$ before and after hoeing at low and high substratum penetrability for control, medium and high damage.

Fig. 2 Posidonia oceanica. Temporal changes in mean $( \pm S E)$ number per shoot $(n=12)$, longest leaf length per shoot $(n=12)$ and shoot density $(n=6)$ during the study period at low and high substratum penetrability. 
Table 1 Analysis of variance on $P$. oceanica shoot density, longest leaf length and leaf number per shoot with two different types of substratum penetration (high vs. low) one year after performing damage intensity (control, medium and high) at the two experimental areas. Shoot density was estimated in each experimental units $(n=3)$, while leaf length and number were estimated in duplicate in each experimental unit $(n=2)$.

\begin{tabular}{|c|c|c|c|c|c|c|c|c|c|c|c|c|}
\hline \multirow[b]{2}{*}{ Source of variation } & & \multicolumn{4}{|c|}{ shoot density } & \multicolumn{4}{|c|}{ leaf length } & \multicolumn{3}{|c|}{ leaf number } \\
\hline & & df & MS & $F$ & $P$ & $\mathrm{df}$ & MS & $F$ & $P$ & MS & $F$ & $P$ \\
\hline Penetration & $=\mathrm{P}$ & 1 & 342.2 & & & 1 & 2.07 & 1.86 & 0.2213 & 0.34 & 0.41 & 0.5457 \\
\hline Damage & $=\mathrm{D}$ & 2 & 1667.6 & & & 2 & 12.68 & 11.43 & 0.0090 & 0.59 & 0.70 & 0.5309 \\
\hline$P \times D$ & & 2 & 299.2 & 5.32 & $0.0166^{*}$ & 2 & 0.31 & 0.28 & 0.7674 & 0.26 & 0.31 & 0.7435 \\
\hline Area $(\mathrm{P} \times \mathrm{D})$ & $=\mathrm{A}$ & 6 & 68.1 & 1.23 & 0.3270 & 6 & 1.11 & 0.16 & 0.9838 & 0.84 & 2.18 & 0.0809 \\
\hline Ex.unit. $(\mathrm{A}(\mathrm{P} \times \mathrm{D}))$ & & 24 & & & & 24 & 6.73 & 1.45 & 0.1511 & 0.39 & 0.34 & 0.9966 \\
\hline Residual & & 36 & 55.5 & & & 36 & 4.63 & & & 1.15 & & \\
\hline \multicolumn{13}{|l|}{ *on Residual } \\
\hline Cochran's test & & \multicolumn{4}{|c|}{$\mathrm{C}=0.3383 \mathrm{~ns}$} & \multicolumn{4}{|c|}{$\mathrm{C}=0.2430 \mathrm{~ns}$} & \multicolumn{3}{|c|}{$\mathrm{C}=0.1084 \mathrm{~ns}$} \\
\hline
\end{tabular}

Table 1A

SNK test on the interaction term $\mathrm{P} \times \mathrm{D}$ (Table 1) for Posidonia oceanica shoot density:

(i) low (Lp) and high (Hp) substratum penetration; (ii) damage intensity, control, medium and high. $\mathrm{SE}=3.04 \mathrm{df}=24$.

\section{(i) Penetration}

Damage

Control

Medium

High

SNK test on damage factor for Posidonia oceanica leaf length. $\mathrm{SE}=0.21 \mathrm{df}=6$

Control(31.16)=Medium(30.63) $>\operatorname{High}(29.72)$
(ii)
Damage

Penetration

Hp Control $>$ Medium $>$ High

Lp Control $>$ Medium=High 


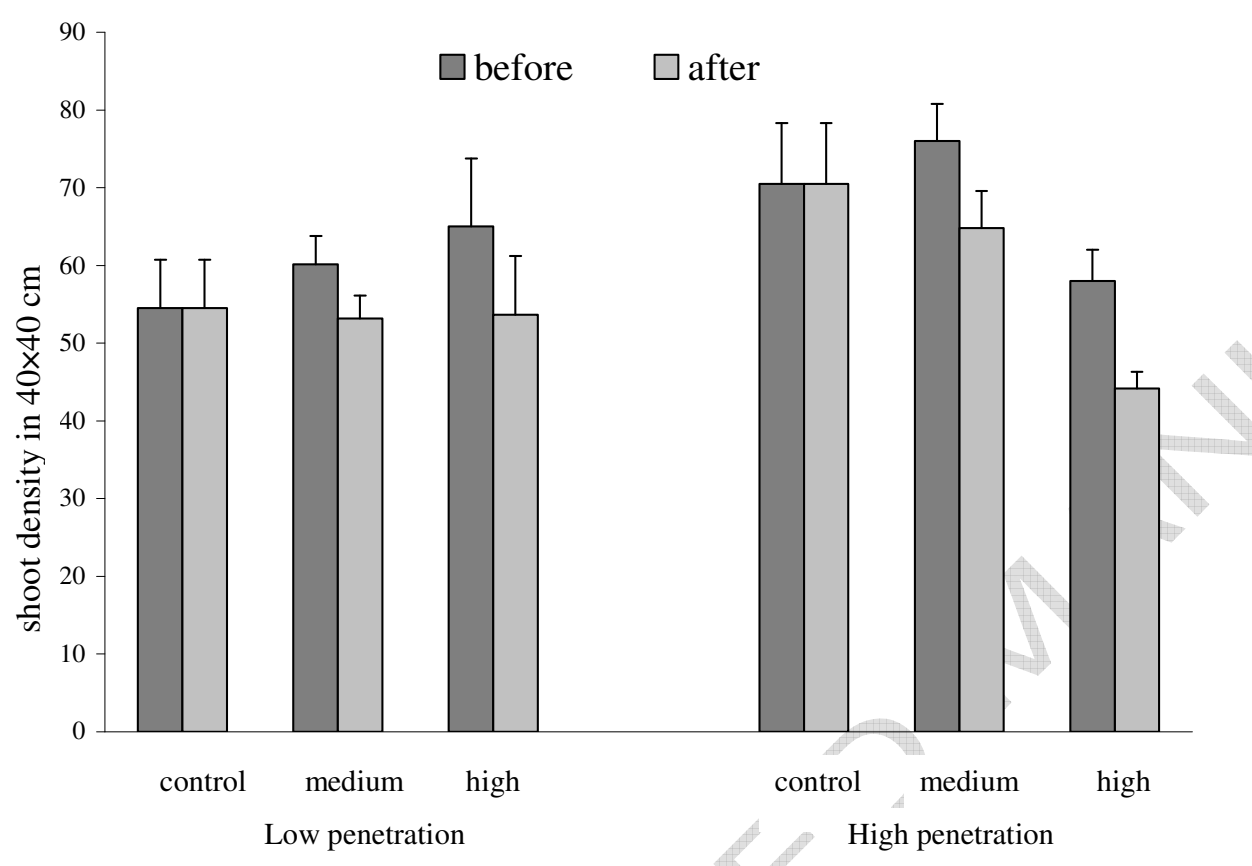

Fig 1: 




